\title{
EL ROL DEL DERECHO INTERNACIONAL EN LA TEORÍA FICHTEANA DEL ESTADO Y LA \\ PROPIEDAD
}

\section{THE ROLE OF THE INTERNATIONAL RIGHT IN THE FICHTEAN THEORY OF THE STATE AND THE PROPERTY*}

\author{
Héctor Óscar ARREse IGOR** \\ Universidad Nacional de La Plata
}

\begin{abstract}
RESUMEN: En este trabajo intento mostrar, contra la tesis de D. James, que existe una relación de continuidad entre la teoría del derecho internacional del Fundamento del derecho natural y de El Estado comercial cerrado de Johann G. Fichte, basándome en dos razones. En primer lugar, en ambos textos la propiedad de los ciudadanos puede ser garantizada sólo si el Estado es soberano en relación con los demás para planificar su propia política económica. En segundo lugar, si bien en El Estado comercial cerrado se restringen las relaciones comerciales entre los ciudadanos, también quedan abiertos otros tipos de relación entre los ciudadanos de diferentes Estados.
\end{abstract}

PALABRAS ClAVE: Estado, guerra, Fichte, paz, comercio.

ABSTRACT: In this paper I try to show, against the thesis of D. James, that there's a relationship of continuity between the international right's theory of the Foundation of the natural right and of The Closed Commercial State by

* El autor forma parte del Proyecto de investigación PICT Raíces 20061795 de la Agencia Nacional de Promoción Científica y Tecnológica (República Argentina).

** E-mail del autor: harreseigor@gmail.com 
Johann G. Fichte, basing my argumentation upon two reasons. In the first place, in both texts the citizen's property can be guaranteed only if the state is sovereing in order to plan its own economical politics. Secondly although in The Closed Commercial State the commercial relationships between the citizens are restricted, other kinds of relationships between the citizens of the differents states also remain open.

KEYWORDS: State, war, Fichte, peace, commerce.

Un año antes de la publicación del primer tomo de su Fundamento del derecho natural (en adelante GNR), es decir hacia 1795, Johann G. Fichte leyó con admiración y luego reseñó Hacia la paz perpetua de Kant ${ }^{1}$. Tanto en la Reseña como en el GNR es evidente la influencia que ha ejercido la recepción del opúsculo kantiano. Baste con mencionar el intento de Fichte de construir una ciencia del derecho autónoma respecto de la ética, o su peculiar lectura de la ley permisiva kantiana, la propuesta de una federación de Estados, o de un derecho cosmopolita, etc.

El derecho internacional de Fichte es un apéndice al GNR pero, como intentaré mostrar en este trabajo, en realidad debería jugar un rol central en la teoría porque, de acuerdo con sus supuestos fundamentales, la garantía del derecho de propiedad de los ciudadanos sólo podría fundarse en la soberanía del Estado en el plano internacional. Por otra parte, Fichte retoma la problemática del derecho internacional en El Estado comercial cerrado (en adelante GHS) de 1800. Allí defiende la tesis de que ningún Estado puede garantizar a sus ciudadanos la propiedad si no restringe dramáticamente su comercio con los demás Estados, porque en caso contrario perdería en autonomía respecto de la planificación de su propia política económica.

D. James sostiene en un trabajo reciente que en GHS Fichte habría abandonado la teoría del derecho internacional del $G N R$, en favor de una limitación tal de las relaciones entre los Estados, que ya no tiene mucho sentido hablar allí incluso de un derecho cosmopolita ${ }^{2}$. D. James funda su argumentación ante todo

\footnotetext{
1 La reseña que hizo Fichte sobre Hacia la paz perpetua puede leerse en SW, VIII, pp. 427 ss.

2 James, (2010).
} 
en el desplazamiento del enfoque metodológico de Fichte, quien en GNR fundamenta el derecho internacional a partir de las relaciones en que pueden entrar los ciudadanos particulares de diversos Estados, mientras que en GHS sólo considera a los Estados como totalidades cerradas en sí mismas, sin tomar en cuenta a los individuos ${ }^{3}$. En segundo lugar, D. James concluye que la propuesta de un Estado comercial cerrado imposibilita las relaciones entre los ciudadanos de diferentes Estados de modo tal que ya no tienen vigencia las tesis del GNR.

Contra la interpretación de D. James, intentaré establecer una conexión conceptual entre la garantía de la propiedad de los ciudadanos y la soberanía jurídica y económica del Estado, en el marco de la teoría de GNR. De este modo, sostendré que no puede hablarse de una distancia insalvable entre las teorías de $G N R$ y GHS.

En este trabajo también intentaré mostrar que Fichte elige en GNR una estrategia incorrecta, al fundamentar el derecho internacional en las relaciones individuales entre los ciudadanos de los diversos Estados. Sin embargo, como bien señala D. James, Fichte abandona en $G H S$ la perspectiva de la intersubjetividad, para tomar al Estado como unidad de análisis. Mi hipótesis consiste en que este deplazamiento quizás puede ser interpretado como un intento por parte de Fichte de subsanar las deficiencias de la propuesta de GNR para el derecho internacional.

Por otro lado sostendré que la teoría de GHS limita sólo las relaciones comerciales entre los ciudadanos de diferentes Estados, por lo cual deja abiertos otros modos de vinculación entre ellos, lo que implica que los planteos hechos en el GNR conservan toda su actualidad en el escrito de 1800 .

Veamos entonces en primer lugar la teoría de las relaciones internacionales expuesta en el GNR.

\section{La teoría fichteana del derecho natural}

En su Fundamento del derecho natural (1796/1797), Johann G. Fichte intenta fundamentar al derecho como una condición de la autoconciencia de cada yo,

\footnotetext{
3 James, (2010), pp. 65-66.
} 
yendo desde el principio general del derecho hacia las diferentes dimensiones del derecho aplicado, tales como el derecho de propiedad, el derecho penal, etc. ${ }^{4}$. El eje de la teoría fichteana del Estado es la protección del derecho originario de cada ciudadano a iniciar cursos libres de acción en el mundo sensible, lo cual exige la garantía de una cierta cantidad de bienes, derechos y prerrogativas 5 . A fin de hacer respetar el derecho originario de cada ciudadano, el Estado debe proveer de los bienes necesarios para que todos puedan mantenerse en la existencia, es decir satisfacer necesidades tales como la nutrición, la hidratación, el cuidado de la salud, etc. ${ }^{6}$.

Fichte desarrolla una teoría compleja de la división del trabajo que se funda en una economía planificada centralmente por el Estado ${ }^{7}$. De acuerdo con este esquema, la clase social fundamental debe ser la de los productores, quienes deben obtener de la naturaleza la materia prima para satisfacer las necesidades que hacen a la subsistencia de los ciudadanos ${ }^{8}$. Pero también son necesarios los artesanos, cuya tarea consistirá en elaborar y manufacturar la materia prima obtenida por los productores, en orden a la fabricación de utensilios, vestidos, etc. ${ }^{9}$. Finalmente, la clase de los comerciantes tiene el rol de mediar entre los productores y los artesanos, para hacer posible el intercambio entre las materias primas y las mercancías ${ }^{10}$.

Fichte considera que el poder ejecutivo debe centralizar también las funciones legislativa y judicial en sus manos, porque de otro modo el egoísmo de los ciudadanos conduciría a la desintegración social y al retorno al estado hobbesiano de la guerra de todos contra todos ${ }^{11}$. El supuesto del egoísmo universal exige el diseño de un sistema legal fundado en la coacción sobre las voluntades, que consiste en la utilización del autointerés de los ciudadanos para lograr que ellos

${ }^{4}$ En adelante citaré esta obra con la abreviatura $G N R$.

5 GNR,\$ 10; SW, III, 113. Para una discusión de la teoría fichteana del derecho originario, Cfr. Horstmann, (2001).

${ }^{6}$ GNR, $\$ 18 ;$ SW, III, 212.

7 Al respecto, Cfr. Batscha (1970) y (1981).

${ }^{8}$ GNR, $\$ 19 ;$ SW, III, 217 ss.

9 GNR, $\$ 19 ;$ SW, III, 231 ss.

${ }^{10} G N R, \$ 19 ;$ SW, III, 234 ss.

$11 G N R, \S 16 ;$ SW, III, 166. En la medida en que Fichte rechaza la división de poderes, se distancia claramente del proyecto kantiano (Oncina Coves, 1994, 333-334). Cfr. también Maus, (2001). Acerca del supuesto del egoísmo universal, Cfr. GNR, \$20; SW, III, 273. 
sirvan al bien común, por miedo a las sanciones y los perjuicios que les sobrevendrían en el caso de no cumplir con la ley ${ }^{12}$. Si los ciudadanos buscan incrementar todo lo posible sus libertades, privilegios y propiedades, entonces no puede contarse con su participación en la toma de decisiones comunes, porque esto pondría en peligro el sistema de coacción, que es el eje de la vida estatal.

Sin embargo, el pueblo se reserva la facultad de controlar el accionar del gobierno por medio de la institución del eforato, quien deberá fiscalizar la constitucionalidad de sus decisiones ${ }^{13}$. Si se diera el caso de que los éforos encuentren alguna irregularidad de una gravedad considerable, deberán denunciarla y dictar el interdicto, suspender la legalidad de los actos de gobierno y convocar a la asamblea popular que decidirá el juicio político al gobierno ${ }^{14}$.

Ahora bien, muchos de los ciudadanos del Estado fichteano también están en relación con otros ciudadanos de otros Estados, lo cual plantea una serie de nuevos problemas que Fichte trata en el Segundo Anexo de su GNR, dedicado al Derecho de Gentes, que consideraré a continuación ${ }^{15}$.

\section{EI derecho en las relaciones entre los Estados}

La teoría fichteana del derecho natural implica que todo individuo tiene derecho a coaccionar a quien entre en relaciones con él para que se someta a su Estado, porque ésta es la única mediación que garantiza la propiedad y la libertad que son indispensables para que cada persona pueda actuar en el mundo sensible ${ }^{16}$. No existe ninguna razón para que alguien ponga en peligro su esfera de acción al

12 GNR, $\$$ 14; SW, III, 142. Fichte tomó esta idea principalmente de la Apologie des Teufels de Johann B. Erhard y de Zum ewigen Frieden de Immanuel Kant (Oncina Coves, 1994, 329).

13 GNR, $₫ 16$; SW, III, 161, 163, 442-443. Los éforos son una reminiscencia del sabio platónico (Gelehrte) (Oncina Coves, 1994, 337).

14 GNR, $\$ 16 ;$ SW, III, 177. Al respecto Cfr. Maus, (2001); Verweyen, (1975), 136-137 y Renaut, (1986), 397-398.

15 Kleingeld ubica el cosmopolitismo de Fichte en el contexto del cosmopolitismo alemán del siglo XVIII, dentro del cual Kleingeld distingue seis formas fundamentales. Se trata de las vertientes moral, internacional federativa, legal, cultural, de mercado y romántico. Cfr. Kleingeld, (1999).

$16 G N R, 2$. Anhang, $\$ 1$, SW, III, 369. Fichte parte de los conflictos que se dan entre los ciudadanos de diferentes Estados y de ahí plantea los problemas del derecho de gentes, dado que el Estado es un concepto abstracto y sólo los individuos son concretos y reales (De Pascale, 2001, 198). 
tratar con otra persona cuyo comportamiento no esté sujeto a derecho alguno. Más aún, el yo está obligado por su misma racionalidad a delimitar su esfera de acciones libres de modo tal de dejar otra igual disponible para los demás y, a su vez, exigir a los otros que hagan lo mismo. Por esta razón, si el ciudadano de otro Estado no está dispuesto a unirse al Estado de quien sale a su encuentro, entonces este último tiene derecho a exigirle que se aparte de su esfera de acción.

Pero este razonamiento sería correcto si existiera únicamente un Estado que integrara a toda la especie humana. Por el contrario, en lugares remotos han ido surgiendo a lo largo de la historia diversos Estados que no se conocían entre sí, lo cual es una prueba de que el Estado responde a una necesidad propia de todos los seres racionales y que no es una invención arbitraria. Además la disposición misma de la naturaleza, que ha dividido su superficie por mares, ríos y montañas, ha obligado por necesidad a los hombres a constituirse en diferentes Estados cerrados en sí mismos ${ }^{17}$. Por lo tanto, aquel argumento con el que comenzamos esta sección carece de validez, porque no parece razonable obligar a quien pertenece a otro Estado a que se someta al Estado al que uno pertenece.

Aquellas personas que pertenezcan a diferentes Estados no entrarán necesariamente en relación, salvo que sus esferas de acción se crucen directamente en el mundo sensible ${ }^{18}$. Pero si estos ciudadanos entran en contacto, cada uno tendrá derecho a poner a seguro su propiedad y su libertad ${ }^{19}$. Sin embargo, no tendría sentido que cada uno exigiera del otro que se integre a su Estado, porque sus exigencias se anularían recíprocamente. De todos modos, ninguno podrá poner sus derechos a resguardo si no se someten a un juez común para los conflictos que los afecten a ambos. Esto implica que cada juez debe tratar a aquel ciudadano de su país, que cometa algún delito contra un extranjero, del mismo modo en que lo hubiera hecho si hubiera agredido a un conciudadano ${ }^{20}$.

$17 G N R$, 2. Anhang, $\$ 2$, SW, III, 369-370. Aquí resuena el eco de la tesis kantiana de que la naturaleza ha previsto que los hombres puedan habitar en todas las regiones de nuestro planeta, habiéndolos empujado hacia diferentes lugares por medio de la guerra, que a su vez los ha obligado a entablar relaciones más o menos legales (ZeF, AA, VIII, 362).

18 Es decir que ejerzan «(...) una influencia recíproca y real» $(F D N, 412) ; G N R, 2$. Anhang, $\$ 3$, SW, III, 370 .

19 El punto de partida es análogo a la ausencia de derechos (Rechtslosigkeit) y de garantías de la propiedad en el contrato social (De Pascale, 2001, 200).

${ }^{20} G N R, 2$. Anhang, $\$ 4$, SW, III, 370-371. 
Por lo tanto, los Estados se verán obligados a suscribir un contrato con la siguiente cláusula: «(...) me hago responsable de todos los daños que mis conciudadanos pudieran acarrear a los tuyos, bajo la condición de que seas igualmente responsable de todos los daños que tus ciudadanos pudieran acarrear a los míos $»^{21}$. Este contrato no forma parte del contrato de ciudadanía de la teoría fichteana, porque este último reglamenta solamente la convivencia entre los ciudadanos que pertenecen a un mismo Estado. Por lo tanto, este contrato debe ser suscripto explícita y públicamente por los Estados y, posteriormente, debe ser integrado al corpus de la legislación vigente. De este modo, el Estado tendrá de aquí en adelante el derecho de castigar a sus ciudadanos que transgredan estas disposiciones para con los extranjeros.

Este contrato interestatal instaura una relación de reconocimiento recíproco entre los Estados que, sin embargo, deben mantener su autonomía, a fin de poder cumplir con su función de garantizar el imperio de la ley, que les ha delegado cada pueblo. Cada Estado entonces debe evaluar si el otro Estado, con el que entra en relación, posee al menos una cierta legalidad y, por lo tanto, si puede entablar una relación con sus Estados vecinos según derecho, haciendo de juez de sus propios ciudadanos en caso de que atenten contra los ciudadanos de las otras comunidades estatales ${ }^{22}$. Sin embargo, ningún Estado está facultado para emitir juicio alguno acerca de la forma particular en la que se gobiernan los demás Estados, porque esto es atribución del pueblo que integra cada uno de ellos.

En consecuencia, si un Estado no reconoce al otro como una comunidad legal autónoma, está suponiendo que tiene derecho a sojuzgarlo, porque considera que la mera existencia del otro Estado pone en peligro la libertad y la propiedad de los demás. Ahora bien, en la medida en que un Estado no reconoce la legalidad de otro, este último está legitimado para declararle la guerra al primero ${ }^{23}$. A pesar de estas afirmaciones terminantes, Fichte sostiene que es muy difícil que se dé un Estado en el que sus gobernantes no tengan ninguna forma de autoridad sobre

${ }^{21} F D N$, 413. «(...)ich mache mich verantwortlich für allen Schaden, den meine Bürger den deinigen zufügen könnten, unter der Bedingung, dass du gleichfalls verantwortlich seyst für allen Schaden, den deine Bürger den meinigen zufügen könnten» $(G N R, 2$. Anhang, $\$ 4$. Corollaria, SW, III, 371).

${ }^{22} G N R, 2$. Anhang, $\$ 5$, SW, III, 372.

${ }^{23} G N R$, 2. Anhang, $\$$ 6, SW, III, 372-373. 
sus ciudadanos, que les permita garantizar a los demás Estados que ellos respetarán la ley. Con el mero hecho de que un pueblo cuente con una autoridad que pueda estar al mando para conducir una guerra, puede suponerse una cierta forma de orden en general $^{24}$. A modo de ejemplo, Fichte afirma que:

Los republicanos franceses derrotaron una vez tras otra a las potencias coaligadas, mientras éstas dudaban de que incluso tuvieran un gobierno y se preguntaban con quién deberían realmente firmar la paz. Habrían debido informarse, empero, en la fuente más próxima con la que estaban en contacto - aquellos que los derrotaron - sobre quién tenía exactamente el mando en el campo de batalla. Habrían podido saber, quizás, que los mismos que habían dado la orden de vencerlos, habrían podido dar también la orden de dejarlos en paz. Al fin, sólo después de haber sufrido bastantes derrotas, han parado mientes felizmente en esta solución y han descubierto que los franceses debían tener ciertamente un gobierno ${ }^{25}$.

Con la firma del contrato interestatal cada ciudadano se compromete frente a su Estado a respetar no sólo la libertad y la propiedad de sus conciudadadanos, sino también la de los demás Estados, lo que exige que las fronteras sean trazadas con precisión y de modo inequívoco. Pero no se trata solamente de una cuestión de fronteras, sino que también deben reglamentarse los derechos que le competen a cada ciudadano en aquellos ámbitos en que puedan entrar en conflicto con las pretensiones de sujetos extranjeros. Fichte se refiere a cuestiones tales como el derecho de caza, de pesca, de navegación, etc. En estos casos, dice Fichte, «los límites de los ciudadanos se convierten, para los Estados, en límites del Estado» ${ }^{26}$.

${ }^{24}$ El carácter mínimo de las condiciones que pone Fichte para reconocer a un Estado como comunidad legal contrastan con la caracterización del Estado en la Sección de Derecho Constitucional de GNR.

${ }^{25} F D N$, 414-415. «Die fränkischen Republicaner schlugen die coalisirten Mächte einmal über das andere, während diese zweifelten: ob sie auch eine Regierung hätten, und fragten, mit wem sie denn eigentlich Friede schliessen sollten. Hätten sie sich doch bei der nächsten Quelle, mit der sie in Berührung standen, bei denen, von welchen sie geschlagen wurden, erkundigt: wer sie denn eigentlich in der Schlacht commandire? Vielleicht, dass dieselben, die den Befehl gegeben hatten, sie zu schlagen, auch den Befehl hätten geben können, sie in Ruhe zu lassen. Endlich, nachdem sie nur hinlänglich geschlagen sind, haben sie sich auch glücklich auf diesen Ausweg besonnen, und entdeckt: dass die Franken denn doch eine Regierung haben müssten» (GNR, 2. Anhang, $\$ 6, S W$, III, 373).

${ }^{26} F D N$, 415. «Die Grenze der Bürger wird für die Staaten Grenze des Staats» (GNR, 2. Anhang, $\$ 9$, SW, III, 374). 
El contrato interestatal coloca a los Estados firmantes en una posición de igualdad, lo que significa que cada uno se compromete a proteger a los ciudadanos del otro Estado en la medida en que el otro se compromete a proteger a los ciudadanos del primero ${ }^{27}$. Esta reciprocidad entre los Estados contratantes implica que ninguno está obligado a proteger a los ciudadanos del otro con más esmero que el que pone el otro Estado en cuidar de los miembros del primero ${ }^{28}$. Por otro lado, este contrato interestatal tendrá validez sólo si los firmantes cumplen efectivamente con los términos que allí se han establecido. Para que los Estados se aseguren el mutuo cumplimiento del contrato, deberán enviar legados (Gesandten) a los otros Estados, cuya misión será entonces transitoria y contingente. Fichte denomina a estas legaciones como embajadas (Ambassaden) ${ }^{29}$.

Dado que el legado debe controlar que el Estado al que es enviado cumpla con el contrato interestatal, no puede someterse a las leyes y el contralor del Estado anfitrión. Por el contrario, debe responder a las leyes del Estado que lo ha enviado, quien es el único que puede juzgar su comportamiento. El legado queda liberado de la obligación de pagar los impuestos del Estado al que es enviado, dado que no es un ciudadano que pertenezca a esta comunidad y no debe contribuir a su sostenimiento. Sin embargo, en el caso de que abuse de su posición de poder para cometer estafas, contrabandos o diversos tipos de delito, el Estado anfitrión tiene derecho a enviarlo de vuelta a su país de origen y de exigir una reparación a este último ${ }^{30}$.

Fichte entiende al derecho de guerra como un derecho de coacción, que es el eje en torno al cual gira el derecho penal ${ }^{31}$. El derecho de coacción es infinito

27 En la propuesta de Fichte los Estados no tienen derecho a intervenir en un Estado, en el caso de que allí se violen los derechos humanos, sino sólo si este Estado niega los derechos de los ciudadanos de otro Estado. De este modo, no se ve de qué modo la federación de Estados podría garantizar la propiedad de los ciudadanos de sus Estados miembros, que constituye su derecho originario mismo. Cfr. Von Manz, (2008), 191-192.

${ }^{28}$ GNR, 2. Anhang, $\$ 9$, SW, III, 374-375.

29 GNR, 2. Anhang, $\$ 10$, SW, III, 375.

30 GNR, 2. Anhang, $\$ 11$, SW, III, 375-376.

$31 \mathrm{Al}$ entender a la guerra como una forma de coacción para evitar que los sujetos no se reconozcan mutuamente como sujetos de derecho, Fichte trata a las relaciones entre los Estados con la misma lógica que usa para las relaciones de los ciudadanos que conviven en el seno de un Estado. De este modo, los ciudadanos se ven obligados a elegir entre disolverse en un Estado de pue- 
porque quien es castigado ha mostrado anteriormente que es incapaz de cumplir con el derecho y que, por lo tanto, no es confiable y no ofrece garantía alguna de su idoneidad para entrar en una relación legal. En este sentido el Estado contra el cual se inicia la guerra no ha reconocido a los demás Estados como sujetos de derecho y, por lo tanto, es pasible de ser sojuzgado sin limitaciones de ningún tipo, porque ya no puede confiarse en él. Aún en el caso de que el Estado que sufre una guerra repentinamente comience a comportarse según el derecho, los demás Estados no tendrán garantía alguna de que este Estado no esté esperando a una mejor ocasión para volver a agredirlos. De este razonamiento Fichte concluye que «(...) el fin natural de la guerra es siempre la destrucción del Estado contra el que se combate, esto es, el sometimiento de sus ciudadanos» ${ }^{32}$.

Ahora bien, esto no significa que el Estado que inicia la guerra tenga derecho a saquear al país atacado y a tomar a sus ciudadanos como esclavos, porque la guerra no tiene lugar contra la población civil sino contra las fuerzas armadas del Estado atacado. Por lo tanto, una vez que el Estado agresor haya ganado la guerra, los ciudadanos del Estado vencido pasarán a ser ciudadanos del Estado vencedor. Lo mismo ocurrirá con los soldados que han entregado sus armas luego de la rendición ${ }^{33}$. Ningún Estado que inicie una guerra, por mucho que lo asista el derecho, puede ordenar matar a nadie como fin último. En realidad sólo los soldados que luchen frente a frente pueden matar al otro, porque tienen el derecho inalienable a su autoconservación. En consecuencia la finalidad de la guerra con armas de fuego no debe consistir en matar al enemigo, sino más bien en lograr que se aparte de las zonas donde caen las balas, a fin de que se repliegue o se entregue. Por esta razón Fichte condena el uso de francotiradores (Scharfschützen), un recurso poco racional pero muy utilizado en la guerra ${ }^{34}$.

La guerra entonces tiene como única razón de ser el exterminio del otro Estado en tanto que comunidad subsistente por sí misma. El medio más idóneo para lograr este fin y, de este modo, coaccionar a cualquier Estado que viole el contra-

blos o regresar a la violencia de la situación hobbesiana de la lucha de todos contra todos (Villacañas, 1996, 111).

32 FDN, 418. «Also der natürliche Zweck des Krieges ist immer die Vernichtung des bekriegten Staats, d.i. die Unterwerfung seiner Bürger» (GNR, 2. Anhang, \$ 13, SW, III, 377).

33 Cfr. De Pascale, (2001), 205.

34 GNR, 2. Anhang, \$14, SW, III, 377-378. 
to interestatal, consiste en que todos los Estados firmantes unifiquen sus fuerzas armadas de modo tal de ganar una fuerza (Macht) que sea superior a la de cada uno tomada por separado ${ }^{35}$. Sin embargo, esto deja abierta la cuestión de cómo lograr que esta fuerza esté inevitablemente al servicio de una causa justa. Antes de responder a esta cuestión, es necesario hacer algunas aclaraciones preliminares.

En primer lugar, Fichte no propone un Estado de pueblos (Völkerstaat), sino más bien una federación de pueblos (Völkerbund), donde cada uno conserve su soberanía y su autonomía ${ }^{36}$. La razón de esto reside en que todo individuo puede ser coaccionado para que ingrese en un Estado, porque esta es la única manera de entablar con él una relación legal y, por lo tanto, delimitar una esfera de acciones libres para cada uno; pero ningún Estado puede ser coaccionado para que ingrese en esta federación, porque siempre es posible establecer relaciones legales aún fuera de esta comunidad interestatal.

De este modo, la federación de Estados debe ser una unión a la que puedan ingresar los Estados voluntariamente ${ }^{37}$. Esta relación legal consistirá entonces en la firma y el cumplimiento del contrato interestatal, por medio del cual cada Estado reconoce a los demás como una comunidad legal. Por lo tanto, aquel Estado que no suscriba este contrato se ha negado a reconocer por este medio a los demás como comunidades legales independientes y se convierte en un posible blanco de una guerra legítima ${ }^{38}$. Sin embargo, queda abierta la posibilidad de que reconozca a los otros Estados por otras vías.

En los casos en que el Estado acusado haya firmado el contrato pero luego lo haya incumplido, la sentencia deberá fundarse en pruebas veraces de que los

35 GNR, 2. Anhang, $\$ 15$, SW, III, 379.

36 Es decir que Fichte permanece en la disyuntiva kantiana entre la formación de un Estado universal o de una federación de Estados y, al igual que Kant, opta por esta última (Cfr. Villacañas, 1996, 112).

37 GNR, 2. Anhang, $\$ 16$, SW, III, 379-380. Cfr. De Pascale, 2001, 201.

38 J. L. Villacañas señala que el argumento de Fichte es débil porque supone que la única fuente de conflictos posibles entre los Estados viene dada por el incumplimiento de los pactos de reciprocidad respecto del reconocimiento entre los Estados. Es decir que Fichte no toma en cuenta que la violencia puede provenir también de los mecanismos de integración interestatal, que su teoría no tematiza ni prevé. Si los mecanismos fueran inexistentes o nulos, tal como de hecho ocurriría en la propuesta de Fichte, entonces podría surgir la violencia entre los Estados. Cfr. Villacañas, (1996), 113. 
ilícitos han tenido lugar. Si el Estado acusado se rehusara a comparecer ante el tribunal de la federación, esto sería una razón suficiente para considerar que ha incumplido con el contrato interestatal. Podría darse el caso de que el Estado que no ha reconocido a otro no pertenezca a la federación, por lo cual parecería que no tendría obligación de comparecer ante ella. Sin embargo, si el Estado que ha sido atacado u ofendido efectivamente formara parte de la federación, entonces ésta última podría asumir su defensa y tomar su lugar. En este último caso, si el Estado agresor no se presentara ante el tribunal de la federación, se haría pasible de las sanciones correspondientes.

A fin de garantizar la paz entre los Estados, la federación tiene la obligación de fiscalizar que los contratos entre los Estados no den lugar a ambigüedades, es decir que debe cuidar de la precisión de sus términos y cláusulas. La federación de Estados debe garantizar también la publicidad de todos los contratos interestatales y de los juicios y sentencias que tengan lugar en su ámbito ${ }^{39}$.

Pero la federación de Estados no sólo está legitimada para dictar sentencias con ocasión de los conflictos de derechos que puedan surgir, sino que también debe estar en condiciones de ejecutar estas sentencias. Esto será posible sólo por medio de la guerra, porque es la forma que adquiere el derecho de coacción en las relaciones entre los Estados. Para este fin deberá disponer ya sea de un ejército permanente o de un ejército ejecutivo, integrado por las contribuciones de los Estados particulares únicamente para el caso de que se declare una guerra. Fichte opta por la segunda opción, porque considera poco práctica la formación de un ejército federal permanente que deba permanecer ocioso la mayor parte del tiempo ${ }^{40}$.

Ahora bien, no puede evitarse que la federación de Estados pronuncie alguna sentencia injusta, dado que el juicio humano siempre es falible, del mismo modo en que no puede asegurarse que el juicio del pueblo reunido en asamblea siempre sea conforme a derecho. Sin embargo, la federación de Estados es la organización política que mejor garantiza la justicia en el arbitraje de conflictos interestatales ${ }^{41}$.

39 GNR, 2. Anhang, $\$ 17$, SW, III, 380-381.

${ }^{40}$ GNR, 2. Anhang, $₫ 18$, SW, III, 381.

${ }^{41} G N R$, 2. Anhang, $\$ 19$, SW, III, 382. Como señala P. Kleingeld, esta afirmación muestra que Fichte no considera que esté justificada la creencia en que la federación de Estados traerá la paz perpetua (Kleingeld, 1999, 512). 
Fichte considera que, más allá de sus limitaciones, la federación de Estados no debe perder nunca de vista su finalidad fundamental, que consiste en conducir el proceso hacia una paz perpetua entre los pueblos ${ }^{42}$. Por lo tanto, la federación nunca debe considerar a la guerra como un fin en sí mismo, sino más bien como un medio para aquel objetivo supremo que le da sentido a su existencia.

\section{EI abandono de la propuesta de una federación de Estados}

Como puede verse claramente a partir de lo argumentado hasta aquí, Fichte utiliza el mismo concepto de derecho de coacción que propuso para su teoría del Estado, porque confía en que el egoísmo de los gobernantes será utilizado para disuadirlos de atentar contra la soberanía de los demás Estados.

En el marco de su teoría del Estado, Fichte sostiene que los conflictos de derechos que puedan surgir entre los ciudadanos podrán ser dirimidos sólo por un tercero que no esté involucrado en la disputa ${ }^{43}$. A la persona que ha agredido al otro no se le puede otorgar la potestad de coaccionarse a sí misma porque, si tuviera la buena voluntad de respetar al otro, la agresión nunca habría tenido lugar. Por el contrario, si la potestad de coaccionar estuviera en manos de quien ha sido víctima de la agresión, entonces se correría el riesgo de que la víctima actuara movida por la venganza y transgrediera a su vez el derecho. Por lo tanto, el poder de coacción debe ser delegado en el gobernante, quien no debe pertenecer al pueblo, a fin de preservar su imparcialidad.

El problema que presenta la propuesta de Fichte para el derecho internacional consiste en que no hay un tercero que pueda zanjar los conflictos de derechos entre los Estados y que se encargue de aplicar la ley de modo imparcial ${ }^{44}$. La razón de esto reside en que sólo el Estado puede ser el garante de los derechos de propiedad de sus ciudadanos, porque el gobierno no puede compartir el poder con nadie más. De allí el sentido del contrato de transferencia (Übertragungsvertrag), por medio del cual el pueblo le delega todo su poder al gobierno, porque en caso contrario el egoísmo de los ciudadanos conduciría a la desintegración social.

42 GNR, 2. Anhang, $\$ 20$, SW, III, 382.

43 GNR, $\$ 16$; SW, III, 153 ss.

${ }_{44}$ De Pascale, (2001), 201. 
En trabajos posteriores a GNR, tales como Über Machiavelli als Schriftsteller (1807, en adelante $U M S$ ) y el System der Rechtslehre (1812, en adelante $R L$ ), Fichte abandona su propuesta de una federación de Estados, luego de haberla revisado a la luz de la política europea contemporánea ${ }^{45}$. La razón de esto reside en que Fichte no encuentra una garantía de que esta federación no dictará sentencias injustas, porque sus fuerzas armadas quedarían inevitablemente en manos de los Estados más poderosos, que las utilizarían para someter a los más débiles. No puede construirse una tal federación entre los Estados actuales, porque entre ellos reina la mutua desconfianza, lo que conlleva la maximización de las ventajas individuales en el corto plazo ${ }^{46}$.

Fichte concluye que a lo sumo puede aspirarse a un equilibrio entre las potencias, donde cada uno se abstiene de atacar a los demás sólo porque cree que tienen la fuerza suficiente para defenderse. Pero en cuanto sospechen que los otros Estados están en una posición de debilidad el equilibrio se romperá rápidamente y, como consecuencia, aquellos Estados que gocen de una fortaleza relativa intentarán expandirse por todos los medios a su alcance.

Por esta razón los Estados deben estar constantemente a la defensiva. En el caso de que no sufran ningún ataque, pueden utilizar las energías, que se habían destinado a la defensa, con la finalidad de obtener otras ventajas para la comunidad $^{47}$. Los políticos deben tomar conciencia de que aquellos Estados que temen a los mismos enemigos se convertirán en sus aliados contra aquellos pero, ni bien tengan la mínima oportunidad, quebrarán sus $\operatorname{pactos}^{48}$.

Un ciudadano puede darse por satisfecho con los bienes que ya posee al interior de su Estado y abandonar todo intento de acrecentarlos, porque tiene un juez que lo protege en el caso de que alguien intente atacar sus propiedades. Pero esto no ocurre en el nivel internacional, por lo cual un Estado que decidiera no incrementar sus bienes estaría renunciando a existir como tal. Por lo tanto, cada Estado debe procurar extender el radio de su influencia sobre los demás todo lo

45 Cfr. especialmente $R L$, SW, X, 648-649 y Villacañas, (1996), 114; En relación con el estudio sobre Maquiavelo, Cfr. Philonenko, (2003), 55-58.

${ }^{46} R L, \mathrm{SW}, \mathrm{X}, 645-646$.

47 UMS, SW, XI, 422.

48 UMS, SW, XI, 423. 
posible y extirpar de raíz toda posibilidad de que los demás Estados lo perjudiquen. Tampoco debe confiar en la palabra de los demás Estados, sino que debe garantizarse que cumplan con su palabra por medio de la coacción ${ }^{49}$.

Si los políticos siguieran las reglas anteriores no se acabaría la guerra entre los Estados, pero disminuiría sensiblemente, porque no sería ventajoso para nadie atacar a Estados que están armados y a la defensiva. De hecho la mayor parte de las guerras surgen porque el Estado agredido ha despertado en el agresor la confianza en que podría atacarlo exitosamente ${ }^{50}$.

\section{La idea de un Estado comercial cerrado}

Si bien es verdad que Fichte ha hecho una autocrítica de su teoría del derecho internacional expuesta en el $G N R$, considero que no ha tomado en cuenta otro problema de suma importancia. Esta dificultad radica en que el derecho internacional de $G N R$ no está orientado a la solución del problema principal de la teoría fichteana del derecho natural, que consiste en la garantía de la propiedad y la libertad de los ciudadanos al interior de cada Estado.

En el marco del GNR, los ciudadanos se incorporan a la vida civil para proteger su libertad y su propiedad de los ataques de los demás. Por lo tanto, la función esencial del Estado es la garantía de estos derechos fundamentales, que constituyen el núcleo de los derechos de ciudadanía. Una vez establecidos estos principios puede verse el peso que debería tener el derecho internacional en esta teoría. La razón de esto reside en que el Estado no podrá garantizar la propiedad a sus ciudadanos si los demás Estados no le garantizan la esfera de acciones libres que necesita para ello, o sea si no respetan su soberanía. Una vez que se ha celebrado el contrato social y los ciudadanos han formado la comunidad del Estado, reaparece el problema que dio origen al Estado mismo, esto es la necesidad de garantizar la libertad y la propiedad, no ya de los ciudadanos a título particular, sino en tanto que están representados por su Estado frente a los demás Estados.

49 UMS, SW, XI, 424-425.

50 UMS, SW, XI, 425-426. 
Podríamos denominar a esta situación como un segundo estado de naturaleza, que también deberá ser resuelto por medio de un contrato que garantice a los Estados y, por su intermedio, a sus habitantes, la protección contra el ataque que puedan sufrir por parte de otros.

Sin embargo, Fichte no sigue el razonamiento que he venido desarrollando en esta sección, sino que plantea el problema del derecho internacional de otro modo, es decir a partir de la posibilidad de que los ciudadanos de un Estado vean lesionados sus derechos al entrar en contacto con los ciudadanos de otro Estado. Las cláusulas del pacto que fundamenta la federación de Estados parecen insuficientes a la hora de frenar los abusos y atentados contra la propiedad de los ciudadanos al interior de los Estados, porque no regulan la dimensión distributiva de la propiedad, esto es el mercado. Fichte mismo se ve movido a impedir la libre producción y circulación de mercancías al interior de cada Estado, a fin de garantizar a cada ciudadano el derecho a vivir de su trabajo. Sin embargo, en el GNR no se desarrolla una propuesta restrictiva del libre comercio entre los Estados.

De acuerdo con esto sostengo que el GHS puede leerse como un intento de subsanar este déficit de la teoría fichteana anterior a 1800. Fundamento esta afirmación en el punto de partida mismo de GHS, es decir en la necesidad de garantizar el derecho de propiedad de los ciudadanos, en tanto que ejercen tal o cual oficio particular ${ }^{51}$. Fichte sostiene que esto es posible solamente si el Estado tiene el control sobre la producción y la distribución de las mercancías dentro de su territorio, lo que le permitirá regular el flujo de las materias primas y las manufacturas, de modo tal de evitar la escasez de bienes, la inflación, la desocupación, etc ${ }^{52}$.

Pero el Estado no podrá resguardar su soberanía si no se cierra todo lo posible al comercio con los demás Estados, porque las asimetrías económicas entre ellos pueden dañar severamente la salud de la economía de algunos ${ }^{53}$. Podría ocurrir, por ejemplo, que un Estado tenga más recursos naturales, una fuerza de trabajo más cualificada o más capital para invertir y entonces pueda producir una cantidad mayor de mercancías y de mejor calidad que los demás Estados ${ }^{54}$. En

51 GHS, SW, III, 403-411; 422-423.

52 GHS, SW, III, 484-503.

53 GHS, SW, III, 458.

54 GHS, SW, III, 461-462. 
este caso, convertiría a los demás Estados en importadores de sus productos, perjudicando seriamente su industria, con el desempleo que esto acarrea y la emigración consecuente de los afectados hacia los demás Estados. De este modo, el Estado afectado no podría cumplir con su función de garante de los derechos de ciudadanía y quedaría a merced de los demás gobiernos ${ }^{55}$.

En consecuencia, el Estado debe comerciar con los demás solamente en casos de necesidad, para lo cual debe sustituir todas las importaciones que pueda a partir de los recursos genuinos que le ofrezca su territorio ${ }^{56}$. De allí la importancia del concepto de "fronteras naturales», que implica que el Estado deberá procurarse la superficie de terreno y las condiciones climáticas que le permitan disponer de las materias primas para asegurar la actividad industrial y la subsistencia de todos los ciudadanos ${ }^{57}$. Fichte defiende esta tesis de modo tan radical que incluso llega a sostener la racionalidad del comportamiento de un Estado que entra en guerra para ampliar sus límites y anexionar otros territorios hasta lograr sus fronteras naturales ${ }^{58}$.

\section{Algunas consideraciones finales}

Como hemos visto más arriba, la propuesta fichteana de un Estado cerrado limita dramáticamente el comercio internacional. Esto implica que los ciudadanos de cada Estado no ponen directamente en contacto sus esferas de acción con ningún extranjero desde el punto de vista económico, dado que la propiedad es un elemento constitutivo del conjunto de alternativas de acción del que dispone cada sujeto. Sin embargo, las esferas de acción de los ciudadanos de diversos Estados se cruzan en la medida en que sus respectivas comunidades establecen relaciones comerciales mutuas o se niegan a hacerlo. Es decir que Fichte traslada el problema de la regulación de las esferas de acción desde la esfera de la intersubjetividad hacia el ámbito interestatal, pero de ninguna manera lo elimina. Por

55 GHS, SW, III, 462-464; 469-471.

56 Fichte señala, no obstante, que el cierre de las importaciones exige pagar costos muy altos para controlar el contrabando, así como el riesgo del descontento popular (GHS, SW, III, 472475).

57 GHS, SW, III, 482-484. Cfr. Merle, (1997), 233.

58 GHS, SW, III, 481-482. 
esta razón considero, contra la tesis de $\mathrm{D}$. James, que no existe una ruptura radical entre el GNR y el GHS, sino que hay una relación de continuidad entre ambas obras.

Esta unidad entre las dos propuestas también se manifiesta claramente en el espacio que Fichte deja libre para las relaciones entre los ciudadanos de diferentes Estados, que consiste en los intercambios de tipo académico y pedagógico, o aquellos que tienen por finalidad el conocimiento de otras culturas, por no mencionar la socialización de los inventos y descubrimientos científico-tecnológi$\cos ^{59}$. De este modo, los problemas que motivan las reflexiones de Fichte sobre el derecho internacional en el GNR conservan su vigencia en el $G H S$, si bien las relaciones comerciales interestatales están restringidas en el último libro y no necesariamente en el primero.

Aunque Fichte intenta en GHS subsanar las deficiencias de su teoría anterior, deja sin resolver el problema de la relación entre el derecho internacional y la vigencia de los derechos de propiedad de los ciudadanos. Por un lado, no logra diseñar una federación de Estados que administre justicia en el plano internacional, aplicando el derecho de coacción para disuadir a quienes intenten poner en peligro la propiedad de los demás. En segundo lugar, la propuesta de un Estado comercial cerrado queda reñida con el objetivo del establecimiento de relaciones pacíficas entre los Estados, porque el logro de las fronteras naturales de cada Estado se antepone al respeto por la soberanía de las demás comunidades. De este modo, no se resuelve la cuestión de la seguridad militar de cada Estado ni la de su soberanía en el plano de la planificación de la política económica. Fichte no logra entonces dar cuenta del desafío de la construcción de una institución de tipo internacional que asegure el respeto por las fronteras que delimitan el territorio de cada Estado y que, a la vez, regule el mercado de modo tal que ningún Estado dependa del otro para garantizar el derecho a la existencia de sus ciudadanos.

59 GHS, SW, III, 506-507, 512-513. 


\section{Bibliografía}

\section{Abreviaturas utilizadas para citar la bibliografía primaria}

FDN: Fichte, J. G. (1995). Fundamento del derecho natural según los principios de la dotrinca de la ciencia, Traducción española de José L. Villacañas Berlanga, Manuel Ramos Valera y Faustino Oncina Coves, Madrid, Centro de Estudios Constitucionales.

GHS: Fichte, J. G. (1800). Der Geschlossene Handelstaat.

GNR: Fichte, J. G. (1796/1797). Grundlage des Naturrechts nach der Prinzipien der Wissenschaftslehre.

RL: Fichte, J. G. (1812). Das System der Rechtslehre.

SW: (1845 ss.). Johann Gottlieb Fichte: Sämmtliche Werke. Editado por. Immanuel Hermann Fichte. Leipzig. Reeditado en: (1971), Berlín, Walter de Gruyter (se cita con indicación del volumen y de la paginación).

ÜMST: Fichte, J. G. (1807). Über Machiavelli als Schriftsteller und Stellen aus seinen Schriften.

ZeF: Kant, I. (1795). Zum ewigen Frieden, AA, VIII, 343 ss.

\section{Bibliografía secundaria}

BATSCHA, Z. (1970). Gesellschaft und Staat in der politischen Philosophie Fichtes, Frankfurt am Main, Europäische Verlagsanstalt.

- (1981). Studien zur politischen Theorie des deutschen Frühliberalismus, Frankfurt am Main, Suhrkamp Verlag.

Bertomeu, M. J. (2004). «Kant y la propiedad del suelo», Isegoría, 30/2004, pp. 127-134.

De Pascale, C. (2001). «Das Völkerrecht (Zweiter Anhang)»; en: Merle, J. Ch., (ed.), (2001), Johann Gottlieb Fichte. Grundlage des Naturrechts, Berlín, Akademie Verlag, pp. 197-210.

HorstmanN, R.-P. (2001). «Theorie des Urrechts (\$\$ 8-12)», en: Merle, J.-Ch., (Hrsg.), Johann Gottlieb Fichte. Grundlage des Naturrechts, Klassiker Auslegen, Band 24, Akademie Verlag, Berlin, pp. 113-123.

JAMES, D. (2010). Fichte's reappraisal of Kant's theory of cosmopolitan right, History of European Ideas, 36 (2010). pp. 61-70. 
KLeINGeLD, P. (1999), «Six Varieties of Cosmopolitanism in Late Eighteenth-Century Germany», Journal of the History of Ideas, Vol. 60, No. 3 (Jul., 1999), pp. 505-524.

MaUS, I. (2001). «Die Verfassung und ihre Garantie: das Ephorat (\$16, 17 und 21)», en: Merle, Jean-Christope (Hrsg.), Johann Gottlieb Fichte. Grundlage des Naturrechts, Klassiker Auslegen, Band 24, Akademie Verlag, Berlin, pp. 139-158.

- (1997). Justice et progrès, Paris, Presses Universitaires de France.

Oncina Coves, F. (1994). «Para la paz perpetua de Kant y el Fundamento del derecho natural de Fichte: encuentros y desencuentros", Daimon. Revista de Filosofia, n. ${ }^{\circ}$, (1994), pp. 323-339.

Philonenko, A. (2003). Essai sur la philosophie de la guerre, París, Libraire Philosophique Vrin.

Renaut, A. (1986). Le Système de Droit. Philosophie et droit dans la pensée de Fichte, Paris, Presses Universitaires de France.

Verweyen, H. J. (1975). Recht und Sittlichkeit in J. G. Fichtes Gesellschaftslehre, München, Verlag Karl Alber Freiburg.

Villacañas, J. L. (1996). «Fichte, el Estado y el derecho internacional»; en: LópezDomínguez, V. (1996). Fichte. 200 años después, Madrid, Editorial Complutense, pp. 99-116.

Von Manz, H. G. (2008). "The universality of human rights and the Sovereignity of the State in Fichte's Doctrine of Right); en: Rockmore, T., Breazale, D., (eds.), (2008), Rights, Bodies and Recognition. New Essays on Fichte's Foundations of the Natural Right, Ashgate Publishing Company, Hampshire-Burlington, pp. 184-194.

Recibido: 29/05/2010

Aceptado: 28/07/2010 